\title{
A new design method for the transition region of the valve plate for an axial piston pump*
}

\author{
Bing $\mathrm{XU}^{\dagger}$, Ying-hui SUN, Jun-hui ZHANG, Tong SUN, Ze-bing MAO \\ (State Key Laboratory of Fluid Power Transmission and Control, Zhejiang University, Hangzhou 310027, China) \\ †E-mail: bxu@zju.edu.cn \\ Received Sept. 7, 2014; Revision accepted Dec. 3, 2014; Crosschecked Feb. 10, 2015
}

\begin{abstract}
The optimization of the valve plate transition region is an important way of reducing the noise emission for an axial piston pump. However, the optimized methods through simulation or experiment are actually trial and error, and they cannot indicate the precise structural parameters of the valve plate transition region. In this study, a new design method for the transition region of valve plate based on the matching of flow area and reduction of transient reverse flow was proposed, and with which a valve plate was designed. Then, the impact of the flow ripple in the discharge line of an axial piston pump and the pressure overshoot and undershoot in the piston chamber on hydraulic and structural noise for axial piston pump is discussed. The noise reduction effect of the axial piston pump with this valve plate was analyzed by adopting a flow characteristic simulation model. Finally, the results showed that the application of this design method could contribute much to the reduction of the flow ripple and elimination of the pressure overshoot and undershoot. As a consequence, the method can be used in the design of a low-noise open circuit axial piston pump.
\end{abstract}

Key words: Axial piston pump, Valve plate, Flow ripple, Pressure overshoot doi: $10.1631 /$ jzus.A1400266

Document code: A

CLC number: TH13

\section{Introduction}

The use of axial piston pumps is rapidly increasing because of its high power-to-weight ratio and excellent controllability. However, due to the increasingly strict requirements on environmental impact, the noise generation within axial pumps arising from high pressure and speed is receiving growing attention. Generally, noise in an axial piston pump can be classified into two main categories, i.e., fluid borne noise and structure borne noise (Seeniraj and Ivantysynova, 2006a; Vacca et al., 2010). A lot of research has been done to show that flow pulsations in

\footnotetext{
* Project supported by the National Basic Research Program (973 Program) of China (No. 2014CB046403), and the Science Fund for Creative Research Groups of the National Natural Science Foundation of China (No. 51221004)

(D) ORCID: Bing XU, http://orcid.org/0000-0003-0236-7896

(c) Zhejiang University and Springer-Verlag Berlin Heidelberg 2015
}

the pump outlet and cavitation are the main reasons for fluid borne noise, while pressure overshoot and oscillation in the piston chamber result in excitations of structure borne noise, and all of them are mainly determined by the structure of the transition region between the delivery kidney and the suction kidney of valve plate, which is a fundamental component of an axial piston pump (Ivantysyn and Ivantysynova, 2001; Manring and Zhang, 2001; Kim et al., 2004; Ivantysynova et al., 2005; Johansson, 2005; Johansson and Palmberg, 2005; Vacca et al., 2010). Kim et al. (2004) measured the pressure variations in the cylinder, the pressure pulsations in the discharge line, and the pump noise with three types of valve plate with different pre-compression angles and notches. Then, they proposed that pump noise could be reduced using the appropriate pre-compression angle and the V-notch design. Furthermore, Edge and Darling (1986) showed that the momentum of fluid in the 
port place silencing groove accounts for the cylinder pressure undershoot at bottom dead center (BDC) and overshoot at top dead center (TDC). It is also the reason for cylinder pressure oscillation.

There have been many previous studies focused on the optimization of valve plate transition region to reduce noise emission for an axial piston pump (Seeniraj and Ivantysynova, 2006b; Nafz et al., 2008). Manring (2003) investigated the principal advantages of various valve plate slot geometries within an axial piston pump. A methodology for designing a swash-plate axial piston pump, whose barrel kidneys are wider than the bridges separating the kidney ports on the valve plate, was introduced by Mandal et al. (2012). They also performed a detailed parametric study on the effect of groove geometries in terms of groove volume, slope, and angular extent (Mandal et al., 2008). Johansson and Palmberg (2005) designed an air drain groove for suction port timing, which gives the same effects as the traditional pressure relief groove. They also proposed that a valve plate with poorly designed suction port commutation produces about 7-8 $\mathrm{dB}$ more noise than a valve plate with a smooth de-compression zone. However, although there were extensive studies on the optimal structure of valve plate transition region, most of them merely verified the effects of the valve plate transition region on pressure variation in the piston chamber, or provided a comparison of noise reduction among valve plates with different transition regions, or optimized the parameters of the valveplate slot with a known structure of transition area, such as a triangular groove, a rectangular groove, and U-notch, by simulation and experiment. In fact, these optimization methods through simulation or experiment are actually trial and error, so they could not indicate the precise structural parameters of the valve plate transition region. As a result, since one cannot generalize from them, they are not versatile in establishing a complete method for designing the distribution of the valve plate.

Using a thorough analysis of the formation mechanism of pump noise emission, this paper proposes that the mismatch between the rate of flow area change and axial piston velocity change is the main factor for producing flow ripple and pressure over- shoot. In addition, the transient reverse flow is also determined by that flow area. Then, a complete design method for the transition region of valve plate is proposed giving the matching of flow area and the reduction of peak value of the transient reverse flow by making it evenly distributed. A valve plate for a certain type of axial piston pumps is designed according to the new method, and the effects on flow pulsations and pressure overshoot are analyzed. Finally, some promising results are obtained, which prove that the proposed design method can be used in the design of a low-noise open circuit axial piston pump.

\section{Simulation model}

The test rig for output flow pulsations and the simulation model for flow characteristics and pressure overshoot of piston chamber of axial piston pump were established in accordance with the method of Ma et al. (2010). The simulation model was improved by $\mathrm{Xu}$ et al. (2013). The comparison and analysis between test and simulation results indicate that the theoretical simulation model is of high accuracy and can be used to guide the design of the valve plate (Ma et al., 2010; Xu et al., 2013).

\section{Mechanism of axial piston pump noise emission}

Axial piston pump noise includes fluid noise and structure noise. The flow pulsations in the discharge line of the axial piston pump are the primary cause of fluid noise. For instance, the pressure ripple of the system converted from flow ripple under the action of load impedance can lead the piston pump and downstream hydraulic components, such as pipeline, hydraulic valves, and cylinders, to vibrate, which produces noise. The excitation of structural noise is the pressure overshoot in the piston chamber. The vibration caused by pressure overshoot can be transmitted to parts ranging from the swash plate, shaft, and bearing housing to the pump housing and its end cover, which produces noise (Ivantysynova et al., 2005). 
According to the established simulation model, the formation mechanism of the axial pump output flow ripple and chamber pressure overshoot can be analyzed as described below. Figs. 1 and 2 show the simulation results of an axial piston pump with the displacement of $71 \mathrm{ml} / \mathrm{r}$, at $2.0 \times 10^{7} \mathrm{~Pa}$ working pressure, $1500 \mathrm{r} / \mathrm{min}$ working speed, and $17^{\circ} \mathrm{swash}$ plate angle.

The main feature of the axial piston pump delivery flow ripple is the short-duration backflow from the discharge kidney groove into the cylinder at the beginning of the delivery phase caused by undercompression of the cylinder fluid as the cylinder passes from the suction port to the delivery port (Harrison and Edge, 2000). Fig. 1 shows the relationship between axial piston pump delivery flow ripple and the flow of a single piston chamber. The nine lines with the same shape in the lower portion represent the flow between the single piston chamber and the delivery kidney groove, the solid line in the upper portion represents the actual axial piston pump output flow, and the dashed line in the upper portion represents the flow confluence with elimination of the transient reverse flow.

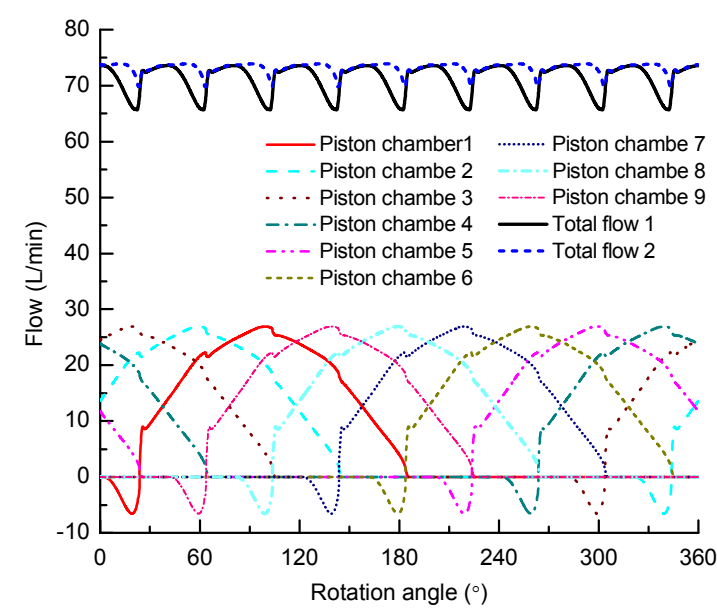

Fig. 1 Flow ripple of an axial piston pump

Furthermore, the positive value of the dotted lines means the fluid flows from the piston chamber to the discharge kidney groove, while the negative value means the reverse condition. The minimum axial piston pump delivery flow, which significantly determines the amplitude of flow ripple, is itself determined by the amplitude of transient reverse flow.
Therefore, for reducing the fluid noise, the transient reverse flow should be decreased.

Piston-chamber pressure changes between high delivery pressure and low suction pressure in one circle is shown in Fig. 2. The pressure of the piston chamber fluctuates because of the pump outlet pressure ripple. In light of that, the piston chamber should complete the transition of pressure before entering into the actual suction and discharge phase. Therefore, if the design of the transition region is unreasonable, the pressure overshoot and undershoot in the piston chamber may occur. At the beginning and the end of the suction phase, the piston chamber produces pressure undershoot owing to its large pressure drop caused by the minor flow area of the piston chamber as shown in Fig. 2. Meanwhile, the piston chamber produces pressure overshoot at the beginning and the end of the discharge phase. Therefore, to reduce the structure noise of the axial piston pump, and eliminate cavitation noise and pressure overshoot in the transition zone, the optimization for the transition zone of valve plate is essential.

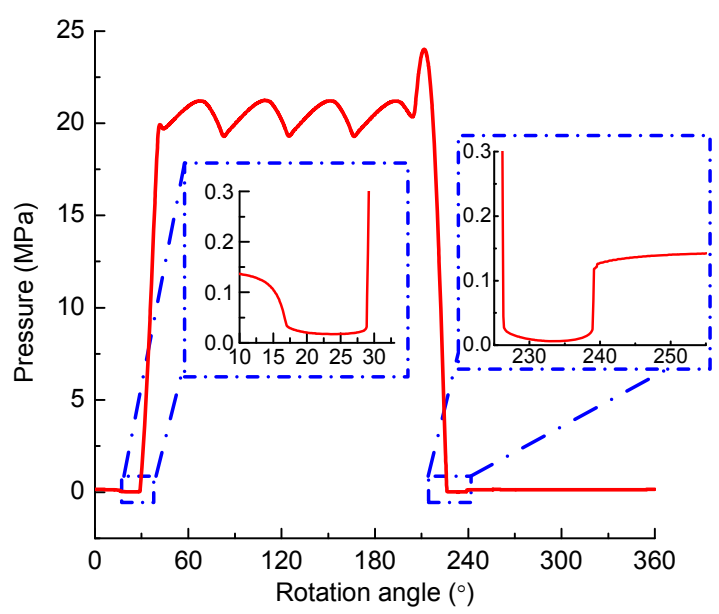

Fig. 2 Pressure variation in piston chamber

In view of the above analysis, there are two main approaches of the new design method in this study for eliminating the pressure overshoot and undershoot and reducing the flow ripple:

1. Matching accurately the flow area between the piston chamber and kidney groove needed by compression and decompression.

2. Reducing the peak value of transient reverse flow by making it evenly distribute. 


\section{Mathematical model}

The transition region of valve plate was designed to reduce transient reverse flow and the pressure overshoot and undershoot in the piston chamber when piston hole diameter, pitch radius of the piston chamber out port, and the piston pump operating parameters are already known. Fig. 3 shows the schematic of the valve plate designed by the proposed method. As depicted in Fig. 3, the transition region of the TDC includes two damping orifices and a relief groove, which connects to delivery kidney groove. The transition region of the BDC includes two damping orifices, which directly connects to the housing chamber and a groove. It should be pointed out that the shape of the damping notch is not limited to triangular.

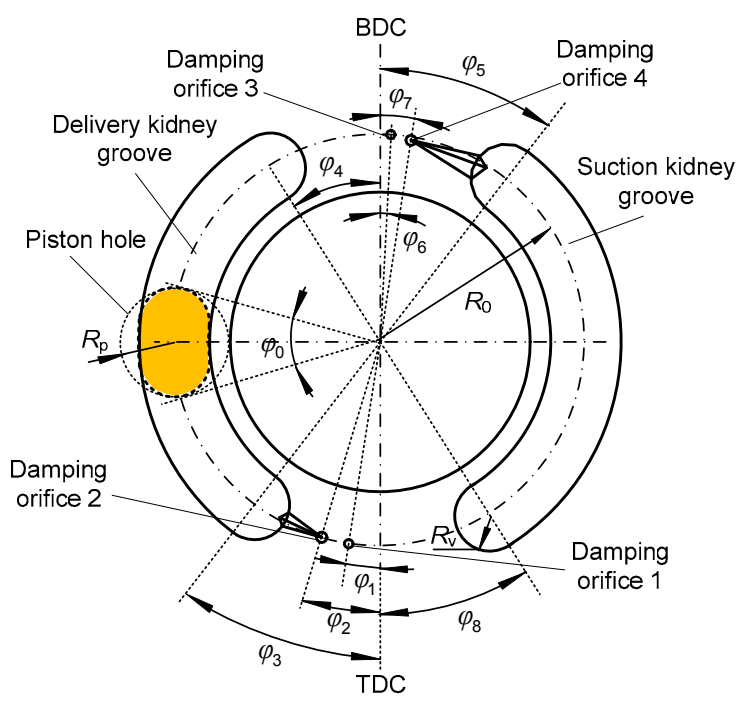

Fig. 3 Schematic of the valve plate

As the cylinder rotates, the piston chamber is connected with the kidney groove on the valve plate. The width and the distribution radius of the kidney groove are equal to those of the piston-chamber out port according to the minimal-pressure-drop principle. The wrap angle $\varphi_{0}$ of the kidney groove is expressed as

$$
\varphi_{0}=2 \arctan \frac{R_{\mathrm{p}}}{R_{0}},
$$

where $R_{\mathrm{p}}$ is the piston hole radius, and $R_{0}$ is the distribution radius of the piston chamber out port.

\subsection{Transition region of TDC design}

The piston chamber accomplishes the transition from suction to discharge when it rotates across the TDC. If it just moves to the TDC when the piston chamber and the suction kidney groove are just fully disengaged, the pressure of the piston chamber can avoid rapid decrease caused by the expansion of oil in a closed vessel, and the piston chamber can avoid connecting with the suction kidney groove when it begins to work at the stage of discharge, which can respectively avoid the phenomenon of cavitation and reduce the internal flow leakage of the axial piston pump. Thus, one of the angles deciding the position of the suction kidney groove is expressed as

$$
\varphi_{8}=\frac{\varphi_{0}}{2}+2 \arcsin \frac{R_{\mathrm{v}}}{2 R_{0}},
$$

where $R_{\mathrm{v}}$ is the radius of the kidney groove.

Fig. 4 shows that, at the end of the suction stage, the flow area shape between the piston chamber and the suction kidney groove is a 'football' that is divided into four parts to calculate the flow area. According to the geometry in Fig. 4, the area $A^{\prime}$ is derived as

$$
A^{\prime}=\int_{0}^{\frac{\gamma R_{0}}{2}} \sqrt{R_{\mathrm{v}}^{2}-\left(R_{\mathrm{v}}-x\right)^{2}} \mathrm{~d} x
$$

where $\gamma$ is the wrap angle of the football-shaped flow area.

Then the flow area $A$ is given by

$$
\begin{aligned}
A= & \left(\gamma R_{0}-2 R_{\mathrm{v}}\right) \sqrt{\gamma R_{0} R_{\mathrm{v}}-\frac{\left(R_{0} \gamma\right)^{2}}{4}}+\pi R_{\mathrm{v}}^{2} \\
& +2 R_{\mathrm{v}}^{2} \arcsin \frac{R_{0} \gamma-2 R_{\mathrm{v}}}{2 R_{\mathrm{v}}} \\
\gamma= & 4 \arcsin \frac{R_{\mathrm{v}}}{2 R_{0}}-(\varphi-\varepsilon), \\
\varepsilon= & 2 \pi-\varphi_{8}+\frac{1}{2}\left(\varphi_{0}-4 \arcsin \frac{R_{\mathrm{v}}}{2 R_{0}}\right),
\end{aligned}
$$


where $\varepsilon$ is the angle the piston chamber turns when the piston chamber outlet and the suction kidney groove ends just composing a circular flow area, and $\varphi$ is the rotation angle of the piston chamber.

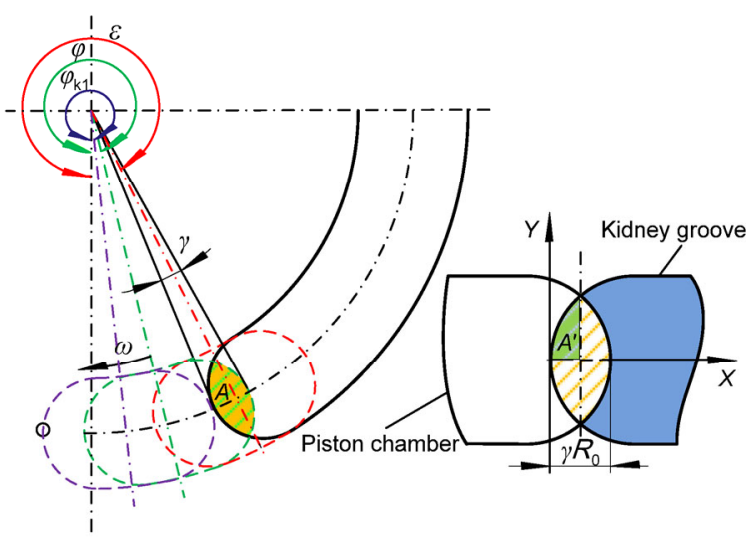

Fig. 4 Piston chamber connects with the end part of the kidney groove

When the rotation angle of the piston chamber is $\varphi_{\mathrm{k} 1}$ as shown in Fig. 4, the piston chamber pressure is equal to the allowable minimum pressure $P_{\mathrm{m}}$. The cavitation will occur if the pressure continues to reduce (Wang, 2010). Therefore, at this point, the piston chamber should connect to the discharge kidney groove so as to replenish the high pressure oil via a damping orifice 1 . Then, the piston chamber pressure caused by the axial movement of the piston chamber will stop decreasing by a small high pressure transient reverse flow. Therefore, the position of the damping orifice 1 is derived as

$$
\begin{gathered}
C A\left(\varphi_{\mathrm{k} 1}\right) \sqrt{\frac{2\left(P_{\mathrm{s}}-P_{\mathrm{m}}\right)}{\rho}}=-\pi \omega R_{\mathrm{p}}^{2} R_{\mathrm{c}} \tan \beta \sin \varphi_{\mathrm{k} 1}, \\
\varphi_{1}=\varphi_{\mathrm{k} 1}+\frac{\varphi_{0}}{2}-2 \pi,
\end{gathered}
$$

where $P_{\mathrm{s}}$ is the suction kidney groove pressure, $\omega$ is the cylinder angular velocity, $R_{\mathrm{c}}$ is the distribution radius of the piston hole, $\beta$ is the inclined angle of the swash plate, $\rho$ is the density of the oil, $C$ is the flow coefficient, and $\varphi_{\mathrm{k} 1}$ is the angle the piston chamber turns when the piston chamber pressure is equal to the allowable minimum pressure $P_{\mathrm{m}}$.

The high pressure oil, flowing from the damping orifice to the piston chamber, is determined by the discharge kidney pressure $P_{\mathrm{d}}$ and the diameter $d_{\mathrm{k} 1}$ of the damping orifice 1 . According to the classical orifice equation, the diameter of the damping orifice 1 $d_{\mathrm{k} 1}$ is given by

$$
\begin{gathered}
C \frac{\pi d_{\mathrm{k} 1}^{2}}{4} \sqrt{\frac{2\left(P_{\mathrm{d}}-P_{\mathrm{m}}\right)}{\rho}}=-\pi \omega R_{\mathrm{p}}^{2} R_{\mathrm{c}} \tan \beta \sin \varphi \\
-C A(\varphi) \sqrt{\frac{2\left(P_{\mathrm{s}}-P_{\mathrm{m}}\right)}{\rho}}, \\
\varphi_{\mathrm{k} 1}<\varphi<2 \pi .
\end{gathered}
$$

From Eq. (6), the maximum value of $d_{\mathrm{k} 1}(\varphi)$ should be selected as the damping orifice radius to avoid cavitation in the piston chamber.

Eqs. (5) and (6) show that, if the geometry parameters of piston chamber were known, the position of the damping orifice 1 is mainly determined by the working speed of the axial piston pump. That means the greater the piston pump working speed, the closer to the suction kidney groove is the damping orifice 1 . Thus, the axial piston pump rated speed should be selected as the design basis so as to prevent the cavitation from occurring over the entire speed range. The parameter $d_{\mathrm{k} 1}$ is determined by the load pressure, and the larger the load pressure, the smaller is the damping orifice diameter. Therefore, the most common minimum pressure should be selected as the design basis.

The piston chamber enters into the precompression phase after passing through the TDC, and it completes the pressure transition from low suction pressure to high discharge pressure under the combined action of the volume compression caused by the axial movement of the piston and the backflow caused by the oil flowing from the discharge kidney groove into the piston chamber. Thus, the angle $\varphi_{2}$ shown in Fig. 3 is given by

$$
\varphi_{2}=\frac{\varphi_{0}}{2}
$$

Supposing the compression effects caused by the piston axial movement and the backflow are separate and sequential, and the pressurization caused by the axial movement of the piston chamber occupies $1 / \mathrm{m}$ of the whole pre-compression of the piston chamber, 
then, according to the fluid elastic modulus formula, we can obtain

$$
\frac{P_{\mathrm{d}}}{m}-P_{\mathrm{s}}=-K_{\mathrm{e}} \ln \frac{V_{\mathrm{p}}\left(\theta_{0}\right)}{V_{\mathrm{p}}(0)},
$$

where $K_{\mathrm{e}}$ is the modulus of fluid elasticity, $\theta_{0}$ is the angle that the piston chamber turns when it completes the process of pre-compression, $V_{\mathrm{p}}\left(\theta_{0}\right)$ is the piston chamber volume when the piston completes precompression, and $V_{\mathrm{p}}(0)$ is the initial piston chamber volume.

According to the pre-compression angle $\theta_{0}$ obtained in Eq. (8), the wrap angle of the delivery kidney groove is given by

$$
\varphi_{3}=\theta_{0}+\frac{\varphi_{0}}{2}+2 \arcsin \frac{R_{\mathrm{v}}}{2 R_{0}} .
$$

Supposing the pressure of the delivery kidney groove to be constant, to achieve the pre-compression of the remaining part in the piston chamber, the total amount of volume $\Delta V$ of the backflow from the kidney groove to the piston chamber is given by

$$
P_{\mathrm{d}}-\frac{P_{\mathrm{d}}}{m}=-K_{\mathrm{e}} \ln \frac{V_{\mathrm{f}}\left(\theta_{0}\right)-\Delta V}{V_{\mathrm{f}}\left(\theta_{0}\right)} .
$$

The peak amplitude of flow ripple at the pump delivery port can be reduced by lowering the peak value of the backflow from the discharge kidney groove to the piston chamber. The easiest way to lower the peak value of the backflow is to make it evenly distributed within the angle $\theta_{0}$. Therefore, without consideration of piston chamber flow leakage, the piston chamber pressure is given by (Ivantysyn and Ivantysynova, 2001)

$$
\begin{aligned}
& \frac{\mathrm{d} P}{\mathrm{~d} \varphi}=\frac{K_{\mathrm{e}}}{V_{\mathrm{p}}}\left(\frac{\Delta V}{\varphi_{1}}-\frac{\mathrm{d} V_{\mathrm{p}}}{\mathrm{d} \varphi}\right), \\
& V_{\mathrm{p}}=V_{\mathrm{p} 0}+\pi R_{\mathrm{p}}^{2} R_{\mathrm{c}}(1+\cos \varphi) \tan \beta, \\
& P(0)=P_{\mathrm{s}}, \\
& P\left(\theta_{0}\right)=P_{\mathrm{d}},
\end{aligned}
$$

where $V_{\mathrm{p}}$ is the piston chamber volume, and $V_{\mathrm{p} 0}$ is the minimum dead volume of the piston chamber. The pressure of the piston chamber in the pre-compression process can be obtained by Eq. (11) and the flow area of the relief groove $A_{\mathrm{h}}$ is given by

$$
\begin{aligned}
\frac{\Delta V \omega}{\varphi_{1}}= & C A_{\mathrm{h}} \sqrt{\frac{2\left(P_{\mathrm{d}}-P(\varphi)\right)}{\rho}} \\
& -\frac{1}{C_{\mathrm{e}}} \frac{\pi d_{\mathrm{k} 1}^{4}}{128 \mu l}\left(P_{\mathrm{d}}-P(\varphi)\right),
\end{aligned}
$$

where $C_{\mathrm{e}}$ is the pressure flow coefficient, $\mu$ is the oil viscosity, and $l$ is the length of the damping orifice 1 .

Then, if the flow area at the beginning of pre-compression process $A_{\mathrm{h}}(0)$ is not quite zero a damping orifice, namely orifice 2 , should be added to the beginning of the relief groove whose radius is given by

$$
\frac{\pi d_{\mathrm{k} 2}^{2}}{4}=A_{\mathrm{h}}(0) .
$$

According to Eqs. (8)-(13), the wrap angle of relief groove and flow area in the process of pre-compression are determined by pressure and the working load speed of the axial piston pump. As the load pressure and speed increase, the angle and flow area also increase. If the rated pressure and rated speed of the axial piston pump are taken as the design basis, the pressure in the piston chamber will become greater than the load pressure instantaneously when the piston pump works with the conditions of low pressure and low speed. However, it will not affect the strength of parts, because the pressure peak is lower than the rated pressure of the pump. Other cases, such as low speed and low pressure, given this design basis, the piston chamber will produce a larger backflow peak because of the shortage of the precompression pressure under the conditions of high pressure and high speed. In short, it is best to regard the rated speed and rated pressure as the design basis.

\subsection{Transition zone of BDC design}

When the piston chamber stays at the end of the discharge stage, the damping orifice 3 connects the piston chamber to prevent pressure overshoot in the 
piston chamber. Thus, the choice of the position and diameter of the damping orifice 3 is the same as that of damping orifice 1. Meanwhile, the design basis for the damping orifice 3 also adopts the rated pressure and rated speed of the piston pump. But $\Delta p$ here represents the maximum allowable pressure overshoot.

The flow area of relief groove of the BDC ensures that the backflow from the piston chamber to the suction kidney groove is constant, whose design is similar to pre-compression relief groove. Another damping orifice 4 is required in the transition region of BDC, for which the design is the same as that of the damping orifice 2 . When the axial pump works at low pressure or low speed, if the rated pressure and rated speed are selected as the design basis, the piston chamber may complete the process of pressure decrease in advance. Then, the piston chamber has to suck oil through the damping orifice at the beginning of suction stage. On the other hand, the cavitation will happen readily owing to the small damping orifice area. Hence, the groove for pre-depressurization should be designed to reduce the backflow peak and prevent the occurrence of cavitation. The design should take the most common working conditions of the axial piston pump as its basis.

\subsection{Valve plate design example}

A new valve plate was designed for a particular commercial axial piston pump with the maximum displacement of $71 \mathrm{ml} / \mathrm{r}$ according to the design method above. The main valve plate design parameters and results are respectively shown in Tables 1 and 2. During the design process, the pre-compression effect caused by the axial movement of the piston chamber is supposed to occupy only half of that in the piston chamber, i.e., $m=2$. Some design results should be rounded during the manufacturing process.

According to the design results, the valve plate has both relief grooves and timing. Furthermore, the wrap angle of the relief groove in the transition region across the TDC is greater than that across the BDC. The reason is that the piston volume is the maximum at the TDC, while the piston volume is the minimum at the BDC. Therefore, achieving the same differential pressure transition, the axial movement and the amount of backflow of the axial piston in the precompression period are slightly more than that in the pre-depressurization period.
Table 1 Main parameters of valve plate design

\begin{tabular}{lc}
\hline \multicolumn{1}{c}{ Parameter } & Value \\
\hline Load pressure $(\mathrm{Pa})$ & $25 \times 10^{6}$ \\
Suction pressure $(\mathrm{Pa})$ & $0.1 \times 10^{6}$ \\
Minimum pressure $(\mathrm{Pa})$ & $0.04 \times 10^{6}$ \\
Rated speed (r/min) & 1500 \\
Maximum swash plate angle (rad) & 17 \\
Piston hole radius (m) & $10 \times 10^{-3}$ \\
Distribution radius of piston hole (m) & $40.5 \times 10^{-3}$ \\
Distribution radius of the piston & $40.5 \times 10^{-3}$ \\
$\quad$ chamber output section (m) & $3.728 \times 10^{-6}$ \\
Minimum volume of piston & \\
$\quad$ chamber (m $\left.{ }^{3}\right)$ & $8.75 \times 10^{-3}$ \\
Length of damping orifices $(\mathrm{m})$ & 0.75 \\
Flow coefficient &
\end{tabular}

Table 2 Results of the design

\begin{tabular}{lc}
\hline \multicolumn{1}{c}{ Parameter } & Value \\
\hline$\varphi_{1}\left({ }^{\circ}\right)$ & - \\
$\varphi_{2}\left({ }^{\circ}\right)$ & 13.87 \\
$\varphi_{3}\left({ }^{\circ}\right)$ & 38.56 \\
$\varphi_{4}\left({ }^{\circ}\right)$ & 25.92 \\
$\varphi_{5}\left({ }^{\circ}\right)$ & 33.13 \\
$\varphi_{6}\left({ }^{\circ}\right)$ & - \\
$\varphi_{7}\left({ }^{\circ}\right)$ & 13.87 \\
$\varphi_{8}\left({ }^{\circ}\right)$ & 25.92 \\
Wrap angle of triangular groove $1\left(^{\circ}\right)$ & 12.65 \\
Wrap angle of triangular groove $2\left(^{\circ}\right)$ & 7.22 \\
Diameter of damping orifice $1(\mathrm{~m})$ & 0 \\
Diameter of damping orifice $2(\mathrm{~m})$ & $0.69 \times 10^{-3}$ \\
Diameter of damping orifice $3(\mathrm{~m})$ & 0 \\
Diameter of damping orifice $4(\mathrm{~m})$ & $0.52 \times 10^{-3}$ \\
\hline
\end{tabular}

\subsection{Calculation of the triangle groove parameters}

The comparisons between the ideal flow area and fitted flow area of transition region at TDC and BDC are respectively shown in Figs. 5a and 5b. The ideal flow area is obtained from Eq. (11). As can be seen from Fig. 5, the new design for the relief groove of the valve plate is just a set of flow areas, so it can be a triangular groove, a U-shaped groove or a combined damping orifice in actual operation. To distribute the transient reverse flow evenly, the flow area increases rapidly at the end of these transition phases. Actually, a slight reduction of transient reverse flow at the end of pressure transition is acceptable. Therefore, the fitted flow area should increase rapidly at the end of 
this phase, while there is no need to match the ideal area precisely. Then, a triangular groove and a cylindrical notch are chosen to fit the ideal flow area to facilitate manufacture. The parameters of a triangular groove calculated by the fminsearch function of Matlab are as given in Table 3.
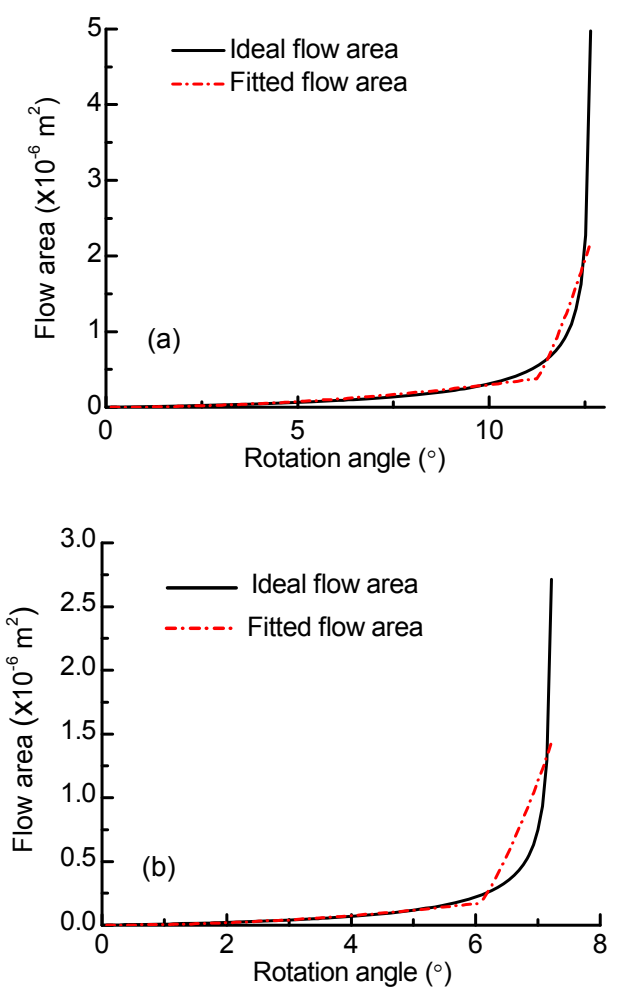

Fig. 5 Flow area at transition region at TDC and BDC

Table 3 Parameters of triangular groove

\begin{tabular}{ccc}
\hline Triangular groove & Width angle $\left(^{\circ}\right)$ & Depth angle $\left(^{\circ}\right)$ \\
\hline TDC & 45 & 6.89 \\
BDC & 45 & 8.60 \\
\hline
\end{tabular}

\subsection{Calculation of the flow area}

The respective instantaneous flow area between the piston chamber and kidney groove on valve plate is the key factor in determining the pressure transition, especially in the transition region where the geometrical cross-sectional area changes sharply due to the relief grooves (Mandal et al., 2008; Xu et al., 2013). This area depends on the angular location of the center of the piston kidney port along with the geometry of the relief groove and the kidney groove
(Mandal et al., 2008). The calculation formula of the flow area should be represented accurately by a piecewise function because its shape changes together with their relative positions (Guan et al., 2014). Taking the rotation of the piston from the kidney groove of the discharge stage to the suction stage as an example, the calculation formula includes several cases:

1. When the piston chamber connects to the damping orifice, the flow area can be simplified to what is shown in Fig. 6, and then the flow area is expressed as

$$
\begin{aligned}
& S_{0}=\frac{\alpha_{1} R_{\mathrm{v}}^{2}}{2}+\frac{\alpha_{2} R_{\mathrm{k}}^{2}}{2}-2 S_{1}, \\
& S_{1}=\sqrt{L_{\mathrm{S}}\left(L_{\mathrm{S}}-L_{\mathrm{k}}\right)\left(L_{\mathrm{S}}-R_{\mathrm{v}}\right)\left(L_{\mathrm{S}}-R_{\mathrm{k}}\right)}, \\
& L_{\mathrm{S}}=\frac{L_{\mathrm{k}}+R_{\mathrm{v}}+R_{\mathrm{k}}}{2} \\
& \alpha_{1}=2 \arcsin \frac{2 S_{1}}{R_{\mathrm{v}} L_{\mathrm{k}}} \\
& \alpha_{2}=2 \arcsin \frac{2 S_{1}}{R_{\mathrm{k}} L_{\mathrm{k}}} \\
& L_{\mathrm{k}}=2 R_{0} \sin \frac{\eta_{0}}{2}
\end{aligned}
$$

where $\alpha_{1}$ is the angle of ADB, $\alpha_{2}$ is the angle of ACB, $S_{1}$ is the area of the triangle ADC, $R_{\mathrm{k}}$ is the radius of the damping orifice, $L_{\mathrm{k}}$ is the distance between centers of the two circles shown in Fig. 6, and $\eta_{0}$ is the wrap angle between centers of the two circles shown in Fig. 6.

2. When the piston connects with the triangular groove, the flow area shown in Fig. 6 can be expressed as

$$
S_{2}=R_{0} R_{\mathrm{v}} \eta_{1} \sin \theta_{1} \arctan \left[\left(R_{0} \varphi / R_{\mathrm{v}}\right) \tan \theta_{1} \tan \frac{\theta_{2}}{2}\right]
$$

where $S_{2}$ is the area of the shaded part in Fig. 6, $\theta_{1}$ is the depth angle of the triangular groove, $\theta_{2}$ is the width angle of triangular groove, and $\eta_{1}$ is the cross angle between triangular groove and the kidney groove shown in Fig. 6.

3. When the piston chamber connects to the end part of the kidney groove, the area is as expressed in Eq. (4). 
4. When the piston chamber connects with the middle part of the kidney groove, the flow area shown in Fig. 6 can be given by

$$
S_{3}=\pi R_{\mathrm{v}}^{2}+2 R_{\mathrm{v}} R_{0} \eta_{2}
$$

where $\eta_{2}$ is the wrap angle between centers of the two circles.

5. When the piston chamber entirely connects to the kidney groove, the flow area shown in Fig. 6 can be expressed as

$$
S_{4}=\pi R_{\mathrm{v}}^{2}+2 R_{\mathrm{v}} R_{0} \varphi_{0}
$$

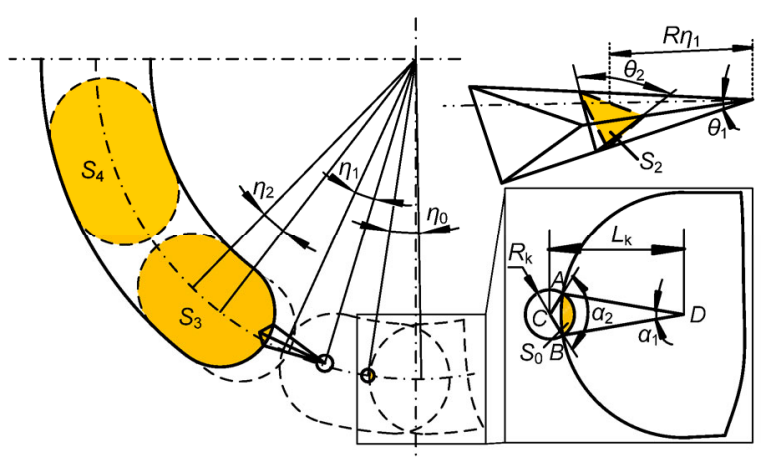

Fig. 6 Different relative positions between piston chamber and valve plate kidney groove

The change of the piston chamber flow area of the original valve plate as well as the new valve plate in a cycle is shown in Fig. 7. Furthermore, the delivery and suction flow areas of the original valve plate are shown as the solid line and the dash line, respectively, while the dash-dotted line and dotted line show the delivery and suction flow area of the new valve plate, respectively.

\section{Results and discussion}

The noise reduction effect of the designed valve plate is analyzed by a simulation model for the flow characteristics of an axial piston pump. The load pressure of the model is $2.0 \times 10^{7} \mathrm{~Pa}$. The working speed is $1500 \mathrm{r} / \mathrm{min}$, and the inclined angle of the swash plate is $17^{\circ}$. Note that the transition region of the original commercial valve plate is designed by the optimized method, which also includes a relief groove and a damping orifice.

The flow changes between the kidney groove in the valve plate and the piston chamber corresponding to different valve plates are shown in Fig. 8. From Fig. 8, we can see that the backflow corresponding to the new valve plate is evenly distributed, and its peak value is much less than that of the original valve plate.

The comparison of the flow ripple for this type of axial piston pump with original valve plate and new valve plate is shown in Fig. 9. The detailed results of the comparison are listed in Table 4, from which we can see that the minimum flow rate of the pump with a new valve plate increases by $0.25 \mathrm{~L} / \mathrm{min}$, the amplitude of flow ripple decreases by $0.23 \mathrm{~L} / \mathrm{min}$, and the flow ripple decreases by $0.24 \%$. Therefore, compared to the pump with the original valve plate, the flow pulsation of the axial piston pump with the new valve plate is reduced.

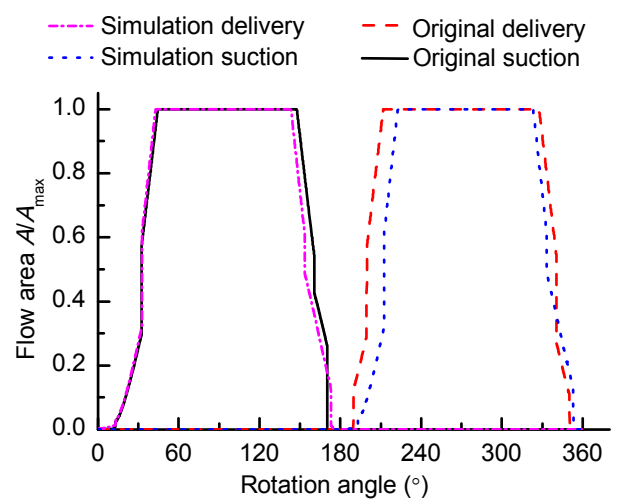

Fig. 7 Variation of flow area between piston chamber and the kidney groove

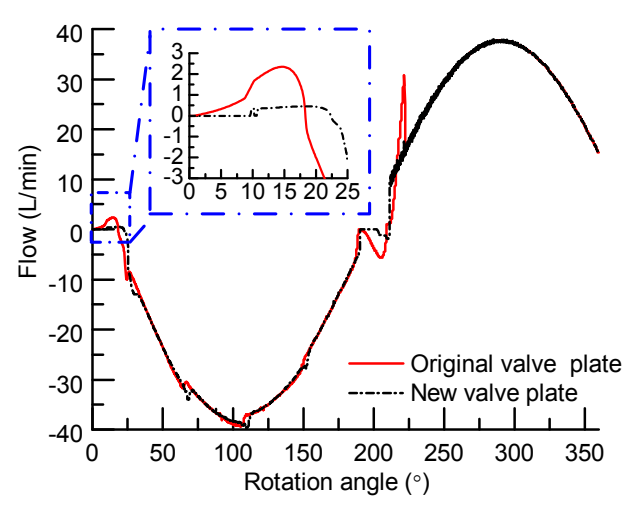

Fig. 8 Comparison of transient reverse flow 


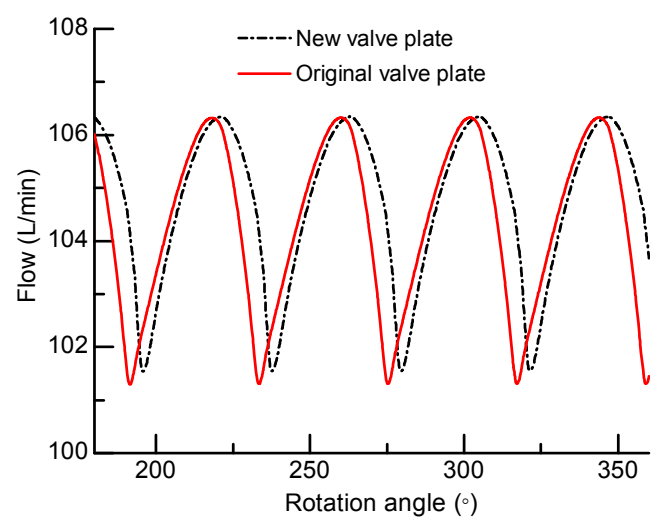

Fig. 9 Flow ripple with different valve

Table 4 Flow ripple with different valve plate

\begin{tabular}{lcccc}
\hline $\begin{array}{l}\text { Valve } \\
\text { plate }\end{array}$ & $\begin{array}{c}\text { Maximum } \\
\text { flow } \\
(\mathrm{L} / \mathrm{min})\end{array}$ & $\begin{array}{c}\text { Minimum } \\
\text { flow } \\
(\mathrm{L} / \mathrm{min})\end{array}$ & $\begin{array}{c}\text { Amplitude } \\
(\mathrm{L} / \mathrm{min})\end{array}$ & $\begin{array}{c}\text { Flow } \\
\text { ripple } \\
(\%)\end{array}$ \\
\hline Original & 106.32 & 101.30 & 5.02 & 4.84 \\
New & 106.34 & 101.55 & 4.79 & 4.60 \\
\hline
\end{tabular}

The comparison of pressure in the piston chamber with different valve plates is shown in Fig. 10. The piston chamber pressure corresponding to the original valve plate in the transition region has two obvious pressure undershoots and one pressure overshoot. Pressure undershoot can lead to air suction and cavitation in the piston chamber. However, for the pump with the new valve plate, pressure undershoot is almost non-existent in the transition region of the piston chamber pressure. In addition, the pressure overshoot in the piston chamber with the new valve plate is considerably reduced. As shown in Fig. 10, although the piston chamber pressure in the early suction stage reduces slightly because the flow leakage is not considered in the design theory and differences exist between the working parameters of design and simulation, the design method for the kidney groove and the transition region of the valve plate helps to reduce pressure pulsations and eliminate pressure overshoot and undershoot of the axial piston pump.

In summary, the design method for the kidney groove and the transition region of the valve plate can significantly reduce the flow pulsations of the axial piston pump and eliminate the pressure overshoot and undershoot of the piston chamber, which helps noise reduction in the axial piston pump. Further, the fitting of the optimal flow area can be achieved by using different structural relief grooves, because this design is not limited to the structure of the relief groove, and thus the method can be of universal applicability.
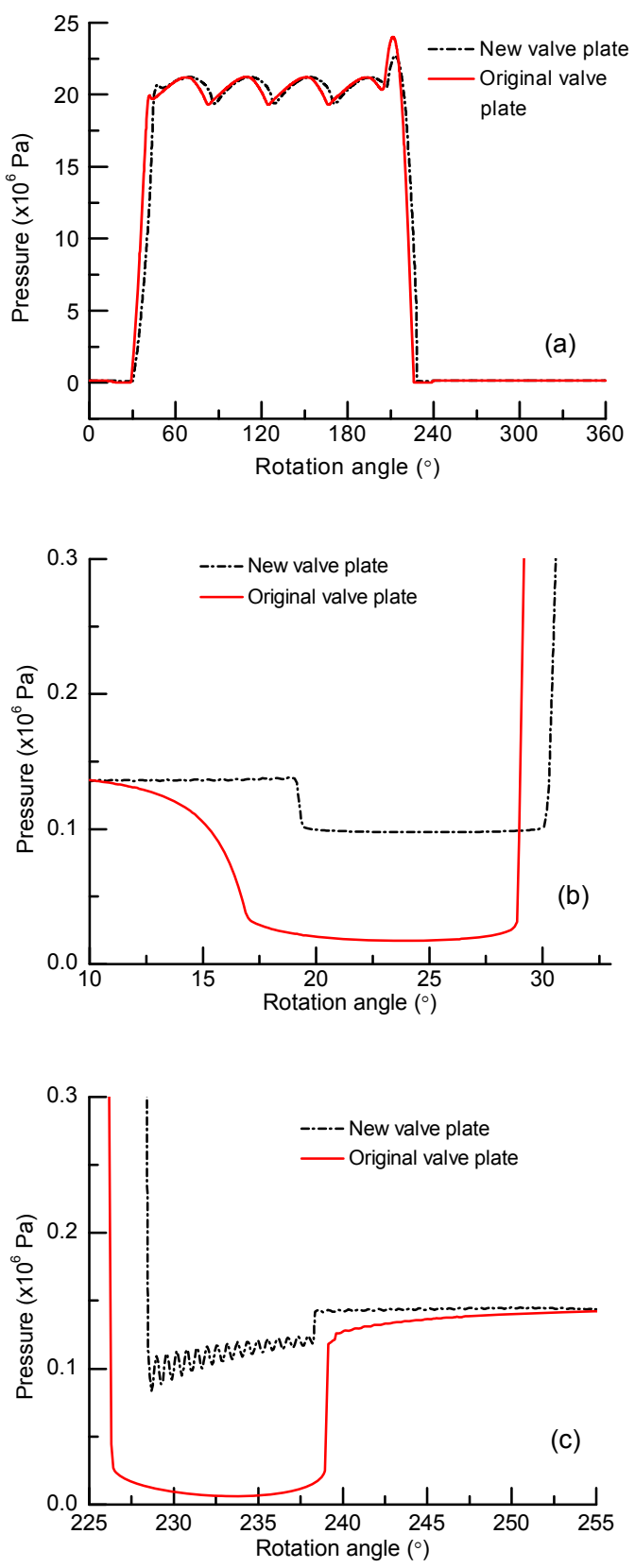

Fig. 10 Comparison of piston chamber pressure with different valve plates

(a) Comparison of piston chamber pressure in a cycle; (b) Magnification of compression process in Fig. 10a; (c) Magnification of decompression process in Fig. 10a 


\section{Conclusions}

The formation mechanism of a noise excitation source is analyzed by adopting a simulation model of the axial piston pump flow characteristics. The amplitude of the flow pulsations in the discharge line is mainly decided by the peak value of the transient reverse flow. Moreover, the mismatch between the rate of flow area change and axial piston velocity change is the fundamental reason for producing pressure overshoot in the piston chamber and the flow pulsations.

A new design method for the kidney groove and the transition area of valve plate is proposed, which targets the elimination of the pressure overshoot and undershoot in the piston chamber and the reduction of the flow ripple in the discharge line of an axial piston pump. The simulation shows that applying the valve plate designed with this new method can reduce the flow pulsations in the discharge line and basically eliminate the pressure overshoot and undershoot in the piston chamber. Thus, the noise is effectively lowered.

The new design method for the kidney groove and the transition area of valve plate is mainly used for open circuit axial piston pumps. However, for closed circuit axial piston pumps, due to the relief groove changing with the interchange between the suction and discharge kidney groove, much more thorough and targeted studies are required. Additionally, the best ratio of the pressure caused by the axial movement of the piston in pre-compression should be optimized in the actual design.

\section{References}

Edge, K.A., Darling, J., 1986. Cylinder pressure transients in oil hydraulic pumps with sliding plate valves. Proceedings of the Institution of Mechanical Engineers, Part B: Journal of Engineering Manufacture, 200(1):45-54. [doi:10.1243/ PIME_PROC_1986_200_047_02]

Guan, C.H., Jiao, Z.X., He, S.Z., 2014. Theoretical study of flow ripple for an aviation axial-piston pump with damping holes in the valve plate. Chinese Journal of Aeronautics, 27(1):169-181. [doi:10.1016/j.cja.2013.07. 044]

Harrison, K.A., Edge, K.A., 2000. Reduction of axial piston pump pressure ripple. Proceedings of the Institution of Mechanical Engineers, Part I: Journal of Systems and Control Engineering, 214(1):53-64. [doi:10.1243/ 0959651001540519]

Ivantysyn, J., Ivantysynova, M., 2001. Hydrostatic Pumps and Motors. Academia Books International, New Delhi, India.
Ivantysynova, M., Seeniraj, G.K., Huang, C., 2005. Comparision of different valve plate design focusing on oscillating forces and flow pulsation. The Ninth Scandinavian International Conference on Fluid Power, Linköping.

Johansson, A., 2005. Design Principles for Noise Reduction in Hydraulic Piston Pumps-Simulation, Optimisation and Experimental Verification. PhD Thesis, Linköping University, Linköping.

Johansson, A., Palmberg, J.O., 2005. The importance of suction port timing in axial piston pumps. The Ninth Scandinavian International Conference on Fluid Power, Linköping.

Kim, J.K., Kim, H.E., Jung, J.Y., et al., 2004. Relation between pressure variations and noise in axial type oil piston pumps. KSME International Journal, 18(6):1019-1025.

Ma, J.E., Fang, Y.T., Xu, B., et al., 2010. Optimization of cross angle based on the pumping dynamics model. Journal of Zhejiang University-SCIENCE A (Applied Physics \& Engineering), 11(3):181-190. [doi:10.1631/jzus.A0900417]

Mandal, N.P., Saha, R., Sanyal, D., 2008. Theoretical simulation of ripples for different leading-side groove volumes on manifolds in fixed-displacement axial-piston pump. Proceedings of the Institution of Mechanical Engineers, Part I: Journal of Systems and Control Engineering, 222(6):557-570. [doi:10.1243/09596518JSCE580]

Mandal, N.P., Saha, R., Sanyal, D., 2012. Effects of flow inertia modelling and valve-plate geometry on swash-plate axialpiston pump performance. Proceedings of the Institution of Mechanical Engineers, Part I: Journal of Systems and Control Engineering, 226(4):451-465. [doi:10.1177/ 0959651811426508]

Manring, N.D., 2003. Valve-plate design for an axial piston pump operating at low displacements. Journal of $\mathrm{Me}$ chanical Design, 125(1):200-207. [doi:10.1115/1. 1541632]

Manring, N.D., Zhang, Y., 2001. The improved volumetricefficiency of an axial piston pump utilizing a trappedvolume design. Journal of Dynamic Systems, Measurement, and Control, 123(3):479-487. [doi:10.1115/1. 1389311]

Nafz, T., Murrenhoff, H., Rudik, R., 2008. Active system for noise reduction and efficiency improvement of axial piston pump. Proceedings of Fluid Power and Motion Control, Bath, UK, p.327-340.

Seeniraj, G.K., Ivantysynova, M., 2006a. Impact of valve plate design on noise, volumetric efficiency and control effort in an axial piston pump. Proceedings of IMECE2006, Chicago.

Seeniraj, G.K., Ivantysynova, M., 2006b. Noise reduction in axial piston pump machines based on multi-paremeter optimization. Proceedings of 4th FPNI-PhD Symposium, Sarasota, p.235-246.

Vacca, A., Klop, R., Ivantysynova, M., 2010. A numerical approach for the evaluation of the effects of air release and vapour cavitation on effective flow rate of axial piston machines. International Journal of Fluid Power, 11(1): 33-45. [doi:10.1080/14399776.2010.10780996]

Wang, S., 2010. The analysis of cavitation problems in the axial piston pump. Journal of Fluids Engineering, 132(7): 
074502-1-6. [doi:10.1115/1.4002058]

Xu, B., Zhang, J.H., Yang, H.Y., 2013. Simulation research on distribution method of axial piston pump utilizing pressure equalization mechanism. Proceedings of the Institution of Mechanical Engineers, Part C: Journal of Mechanical Engineering Science, 227(3):459-469. [doi:10.1177/ 0954406212462336]

\section{中文概要}

\section{题 目: 一种新的轴向柱塞泵配流盘过渡区设计方法}

目 的：轴向柱塞洜配流盘的过渡区是影响轴向柱塞泵噪 声的重要因素之一。本文提出一种新的过渡区设
计方法, 旨在降低轴向柱塞原的噪声。

创新点：1. 该方法设计的过渡区结构, 使得柱塞腔与配流 盘腰形槽之间的通流面积完全匹配柱塞腔预升 压与预降压所需求的面积; 2. 优化倒灌流量在倒 灌区间内的分配。

方 法: 1. 计算柱塞腔预升压与预降压所需求的柱塞腔与 配流盘腰形槽之间的通流面积; 2. 将柱塞腔倒灌 流量平均分配到倒灌区间内, 从而降低倒灌流量 的峰值。

结 论: 1. 该设计显著地降低了柱塞腔压力的正超调量和 负超调量; 2. 减小了轴向柱塞泵出口流量脉动的 幅值。

关键词: 轴向柱塞泵; 配流盘; 流量脉动; 压力超调 